\title{
Modelling and Optimization of the Air Operational Manoeuvre
}

\author{
Agostino BRUZZONE ${ }^{1}$, Josef PROCHÁZKA ${ }^{2}$, Libor KUTĚJ ${ }^{2}$ and Dalibor \\ PROCHÁZKA ${ }^{2}$, Jaroslav KOZŮBEK ${ }^{2,}$ Radomir SCUREK ${ }^{3}$ \\ ${ }^{1}$ Univerity of Genoa \{agostino@itim.unige.it\} \\ ${ }^{2}$ University of Defence, Brno, Czech Republic \\ \{jan.mazal, josef.prochazka, libor.kutej, dalibor.prochazka, \\ jaroslav.kozubek\} @unob.cz \\ ${ }^{3}$ WSB Uniwersity Dąbrowa Górnicza, Poland \\ \{radomir.scurek@gmail.com\}
}

\begin{abstract}
.
Increasing complexity of the operational environment and advanced technology implementation in combat will probably lead to a serious limitation of human performance in all operational domains and activities in the future. With except of the clear indications, that tactical robotics will outperform human soldiers in many routine tasks on the battlefield, the area of operational decision making (resistible for decades to some automation) seems to be slowly approaching to the same stage. Presented article discusses the fundamental theory of optimization of the air operational maneuver and present the approach to the solution. The solution is highly theoretical and uses a modelling and simulation as an experimental platform to the visualization and evaluation of solution. The problem of air operational maneuver is specific in this case by many variables imposed on initial parametrization of the task (starting and destination point could not be known at the beginning, only "air operational" area should be selected) and very wide search of possible courses of action and the best "multi criteria" choice identification.
\end{abstract}

Keywords: UAV, safety manoeuvre modelling, ISR, optimization, air maneuverer 


\section{Introduction}

Contemporary highly dynamic military operational environment brings many changes and new challenges which were not significant or apparently visible before. One of the today's significant trends in military is continuous pursue for the effectiveness and its improvement in context of lack of qualified personnel. This gives us the motivation for search of the solution of selected operational problems, which could be further partially or fully automated and save the human effort and increase effectiveness in mission execution.

\section{State of the art}

Even thought a lot of publications dedicated to the area of Air/UAV manoeuvre optimization were found, it is still an actual topic.

After a publication analyses, before this paper was written, it could be mentioned, that majority of the papers dedicated to the Air maneuverer optimization area fell to the several sub-topical segments, mainly swarming and formation optimization, many of them are close to the air traffic control tasks, problems related to the traveling salesman problem (TSP) or optimization in collision avoidance, for instance:[1,2,3,4,5,6]. Very few papers were found, which are close to the operational optimization like:[10,11,12], especially in more complex and multi criteria context, when the operational situation is considered.

\section{Approach to the solution}

Following solution is an continuum or more "operational " extension to the solution of "Modelling of the UAV safety manoeuvre for the air insertion operations" published in 2016[11], what was more "tactically oriented" and initial parameters like destination point and UAV take-off point was known.

In this case we were interested in the best (safeties) and stable 3D flight path through the restricted flight corridor from the north to the south. It means that we search the entry and exit point where airplane (UAV) penetrate the "north" and "south" plane of the 3D corridor and path between these points fulfilling following optimization condition:

where:

$$
A I R_{\text {path }}=\min \rightarrow \sum_{i=1}^{M} A_{I_{i}, J_{i}, K_{i}}
$$




$$
\begin{array}{ll}
A_{x, y, z}- & \text { 3D safety matrix of operational area, derived from the set } \\
\text { of analyses (3) } \\
\text { are the mathematical progressions coding the individual } \\
I_{i}, J_{i}, K_{i}-\quad
\end{array}
$$

The condition:

$$
\forall i \in(1 . . M)=>\left(\left|I_{i+1}-I_{i}\right|+\left|J_{i+1}-J_{i}\right|+\left|K_{i+1}-K_{i}\right|\right)<3,
$$

means that that two following elements of $A$ matrix are adjacent. Also, because of the initial condition, were entry and exit points are not specified, the solution search for the best:

$$
\begin{aligned}
& \boldsymbol{A}_{\boldsymbol{I}_{\boldsymbol{i}} \boldsymbol{J}_{i}, \boldsymbol{K}_{i}} ; \boldsymbol{i}=\mathbf{1}- \text { entry point of the flight, must lay on the "north" plane of } \\
& \text { the cuboid representing a 3D air operation area. } \\
& \boldsymbol{A}_{\boldsymbol{I}_{\boldsymbol{i}} \boldsymbol{J}_{i}, \boldsymbol{K}_{i}} ; \boldsymbol{i}=\boldsymbol{M}- \text { exit point of the flight, must lay on the "south" plane of } \\
& \text { the cuboid representing a 3D air operation area. }
\end{aligned}
$$

Schema presenting the placement of the operational areas is depicted on following figure 1. Were $\mathrm{EL}_{\mathrm{OR}}$ shows the operating area for enemy forces with "light" weapons (affecting 3D AOA in a different way than enemy with "heavy" weapons), and $\mathrm{EH}_{\mathrm{OR}}$ present the operating area for the enemy forces with "heavy" weapons, limited with their maneuver to the roads (indicated by the green crosses), contrary to the enemy forces with "light" weapons (they are not limited to the roads with their ground movement).

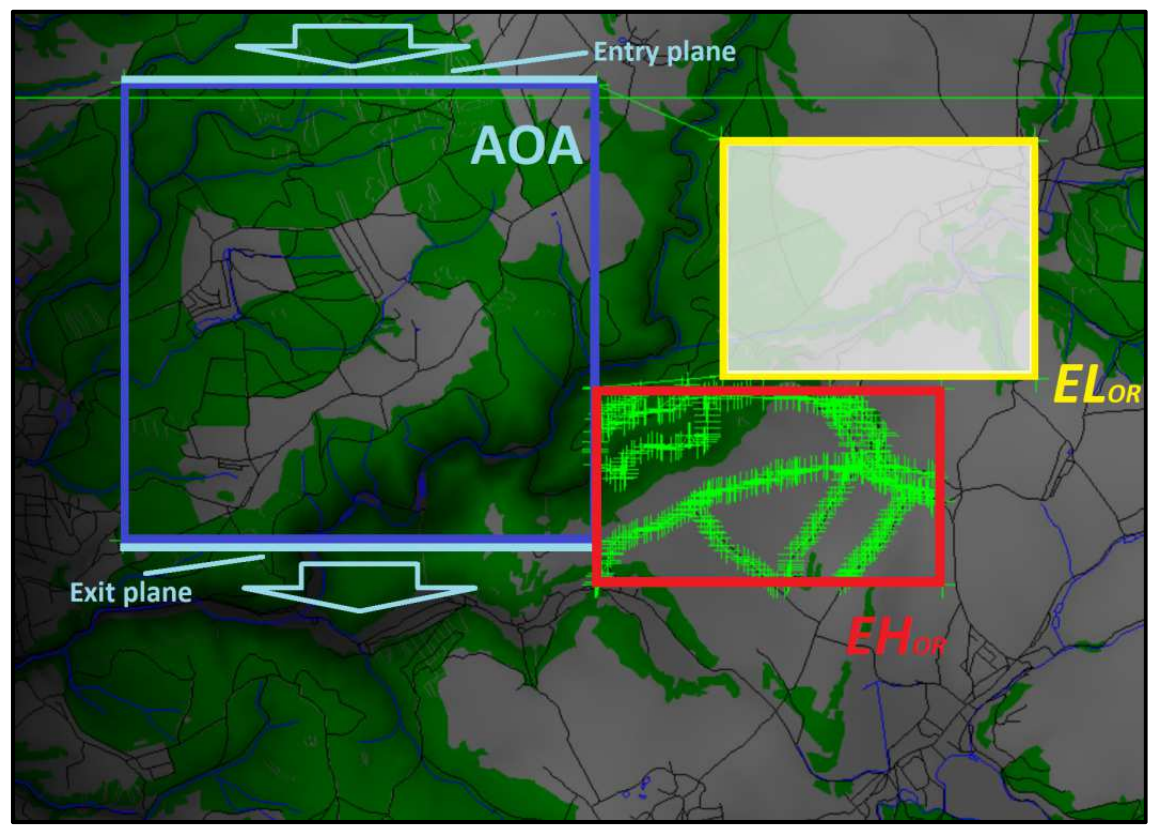


Fig. 1.: Schema presenting the placement of the operational areas, AOA-Area of Operational Air Maneuver, $E H_{O R}$ represents the operating area for the enemy forces with "heavy" weapons, $E L_{O R}$ shows the operating area for enemy forces with "light" weapons, from the computer application developed by the authors.

Calculation of the 3D safety matrix includes set of analyses linked to set selected criteria in the Air Operational Area - AOA. Set to of these analyses could be fully or partially automated in context of updated operational situation, the latest data are usually available in C4ISTAR systems. For the mentioned example was selected following approach in calculation of 3D safety matrix:

$$
\begin{array}{ll}
A_{x, \mathrm{y}, \mathrm{z}}=\sum_{\mathrm{m}=1}^{N}\left(S V_{m} \cdot G O A_{m}(x, \mathrm{y}, \mathrm{z})\right) \\
A_{x, y, z} & \text { - } 3 \mathrm{D} \text { safety matrix of operational area } \\
G O A_{m}(x, y, z) & \text { - Geo-operational analyses matrix (storing a partial results) } \\
S V_{m} & \text { - safety weights defining the priorities in analyses in par- } \\
& \text { ticular case of operational task solution }
\end{array}
$$

The count of analyses affecting coefficients of the safety matrix should be linked to the desired purpose and information available from the Operational Area. Security analyses usually represent the partial security aspects to the global security situation and are computed based on commander's priority and selection. Actually calculating the $A_{i}$ coefficients is a separate operational task and it could be based on other additional requirements and expected danger. Also single analyses should be normalized to be weighted and summarized with the others. To experiment with mentioned case we set up following scenario:

- We expect two enemy entity types with two various weapons that can endanger Air manoeuvre (heavy and light).

- The ground maneuverer of the enemy with the heavy weapons is limited to the roads and to the area we suppose them to operate.

- The ground maneuverer of the enemy with the light weapons is limited only to the area we suppose them to operate.

- Due to the mentioned conditions, we could calculate all possible positions for both of the enemy entities and calculate safety coefficient for any (ground and air) point of Air operational Area.

For the purpose of simulation experiments we define some terms and calculate following analyses:

- Air Operational Area as a space for the 3D safety matrix, AOA see Figure 1.

- Area of enemy operation (with heavy and light weapons) as $E H_{O R}$ and $E L_{O R}$.

- Visibility analyses of the all points of AOA from the as $E H_{O R}$ and $E L_{O R}$, named $V A_{O R}$.

- Appearance analysis of the enemy with "light" weapons in the $E L_{O R}$ and threat analyses for the AOA from the $E L_{O R}$ area. 
- Appearance analysis of the enemy with "heavy" weapons in the $E H_{O R}$ and threat analyses for the AOA from the $E H_{O R}$ area.

- Specification of the Air manoeuvre constraints.

Whole solution is rather complicated, consists of several thousand lines of $\mathrm{C}++$ code, so the detailed description fells out of the frame of this article, in any case following scheme on figure 2., and generally describes the core procedures/parts of the solution algorithm:

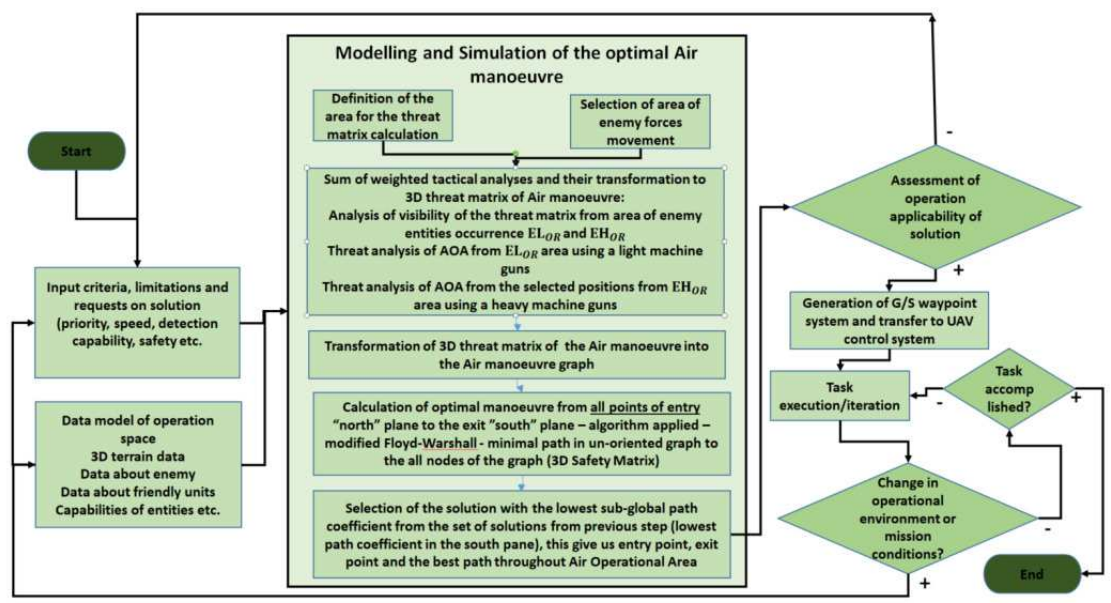

Fig. 2.: Generic algorithm of the solution.

For example of application of individual analyses were used following Geooperational analyses, similarly as in the reference published in 2016 [11]:

Analysis of "light" weapons enemy threat from $E L_{O R}$ operational area:

$$
G O A_{1}=C_{a l k} \cdot F_{v}(S, D) \cdot P_{z l k}(\mathrm{~S}, \mathrm{D}),
$$

Analysis of "heavy" weapons enemy threat from $E H_{O R}$ operational area:

$$
G O A_{2}=C_{a t k} \cdot F_{v}(S, D) \cdot P_{z t k}(\mathrm{~S}, \mathrm{D})
$$

where:

$-C_{a l k}$ is a operational coefficient of a multi-criteria evaluation defined for $\mathrm{GOA}_{1}$ analysis.

$-C_{a t k}$ is a operational coefficient of a multi-criteria evaluation defined for $G O A_{2}$,

$-F_{v}(S, D)$ is a visibility function from the source - S point to the destination - D point on a (digital) terrain model, $0 \leq F_{v}(S, D) \leq 1$.

- $P_{z l k}(S, D)$ is a probability hit of a target at the position of $D(x, y, z)$ using a "light weapon" from the point of $S(x, y, z)$ on terrain model. 
$-P_{z t k}(S, D)$ is a probability hit of a target at the position of $D(x, y, z)$ using a "heavy weapon" from the source point of $S(x, y, z)$ on terrain model.

$-S(x, y, z)$ is the source point on a (digital) terrain model.

$-D(x, y, z)$ is the destination point on a (digital) terrain model.

To demonstrate solution of the problem, a computer application was developed $(\mathrm{C}++)$, where mentioned approaches and algorithms were implemented. The input data for the operating environment were taken from the highly detailed terrain database of the selected region in the Czech Republic provided by GEO service of the Czech Armed Forces. General overview of the map and various operating areas is presented on the figure 1, example of Air path optimality map within AOA calculated from the first initial iteration (means that the first entry $\mathrm{XYZ}$ point was $(1,1,1)$ ), is demonstrated on following figure 3. :

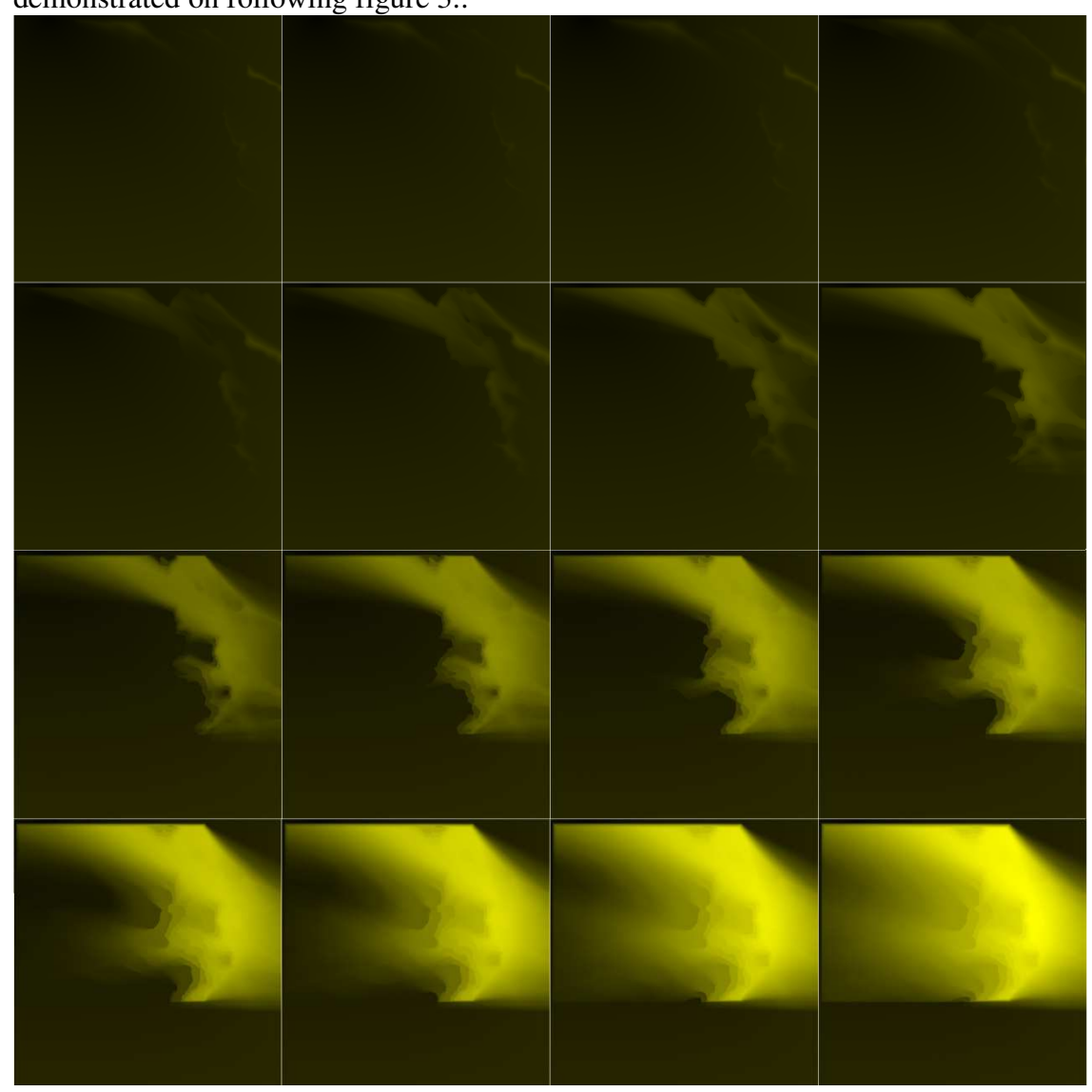

Fig. 3.: 16 cuts (from the ground to top, starting from the top left corner to the bottom right) of $3 D$ Air optimality path map within AOA, darker point is better in terms of the path safety (application developed by the authors). 
On the 3D safety matrix, there were investigated/calculated huge number of optimal paths coming from the each possible entry point on the "north" pane of the matrix $(1, \mathrm{y}, \mathrm{z}),(5000 \mathrm{~m} \times 1600 \mathrm{~m})$. For presentation purpose, the sampling step was degraded up to the $100 \mathrm{~m}$ vertically and $715 \mathrm{~m}$ horizontally. Final Path optimality map from the "south" matrix pane, based on the entry point is demonstrated on the following figure 4., with the red-white dot indicating the best exit point from the AOA/3D safety matrix.

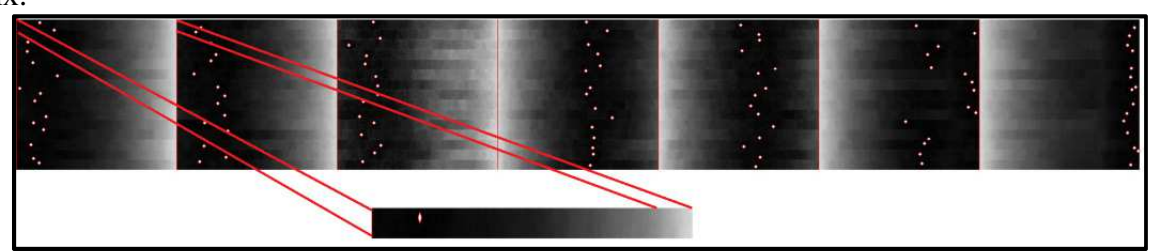

Fig. 4.: The figure is presenting 15x7 = 105 final Path Optimality Maps taken from the "south" matrix pane $(500, y, z)$, with the $10 \mathrm{~m}$ resolution, scale is from black to white (darker is better), red dots indicate the best position for the exit of the AOA within its entry point.

The results of calculations and number of simulated flights is presented on the next figure 5., on right graph, there are presented exit point from the 3D matrix in the "south" pane, on the right graph, there are showed initial sampled entry points in the "north" pane on the 3D matrix (bigger circles) with exit point (same as the right graph) and connection lines represent correspondence between entry and exit point within a single sub-solution/iteration.
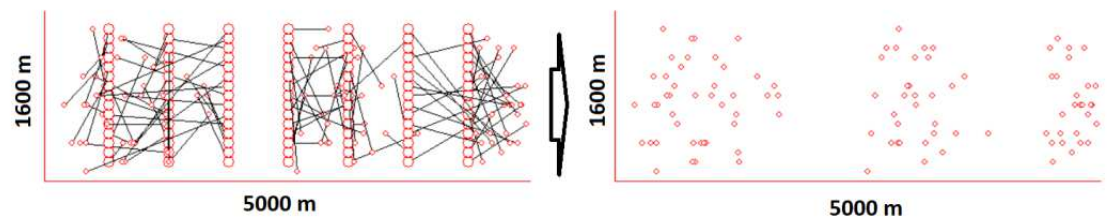

Fig. 5.: Graphs of calculated exit points (right graph) and entry and exit points (left graph) from and to the AOA/3D matrix, left graph also show the linkage between entry and exit point within a single iteration.

Based on a previous search process for the best coefficient from the "exit" pane, consolidating the lowest total sum of possible threat, the optimal solution was easily found from all simulations, searching the lowest coefficient at the exit pane after the Floyd-Warshall algorithm execution. When the best candidate (exit point) was identified, the back search to the entry point was executed and this is depicted on the figure 6 , were the 16 cuts of $3 \mathrm{D}$ path map are demonstrated with appearance of the optimal path in each layer indicated by the red dots. Path search was applied to the non-oriented weighted graph (topology of 26 connecting neighboring cells, totally $512 \times 512 \times 160$ nodes). 


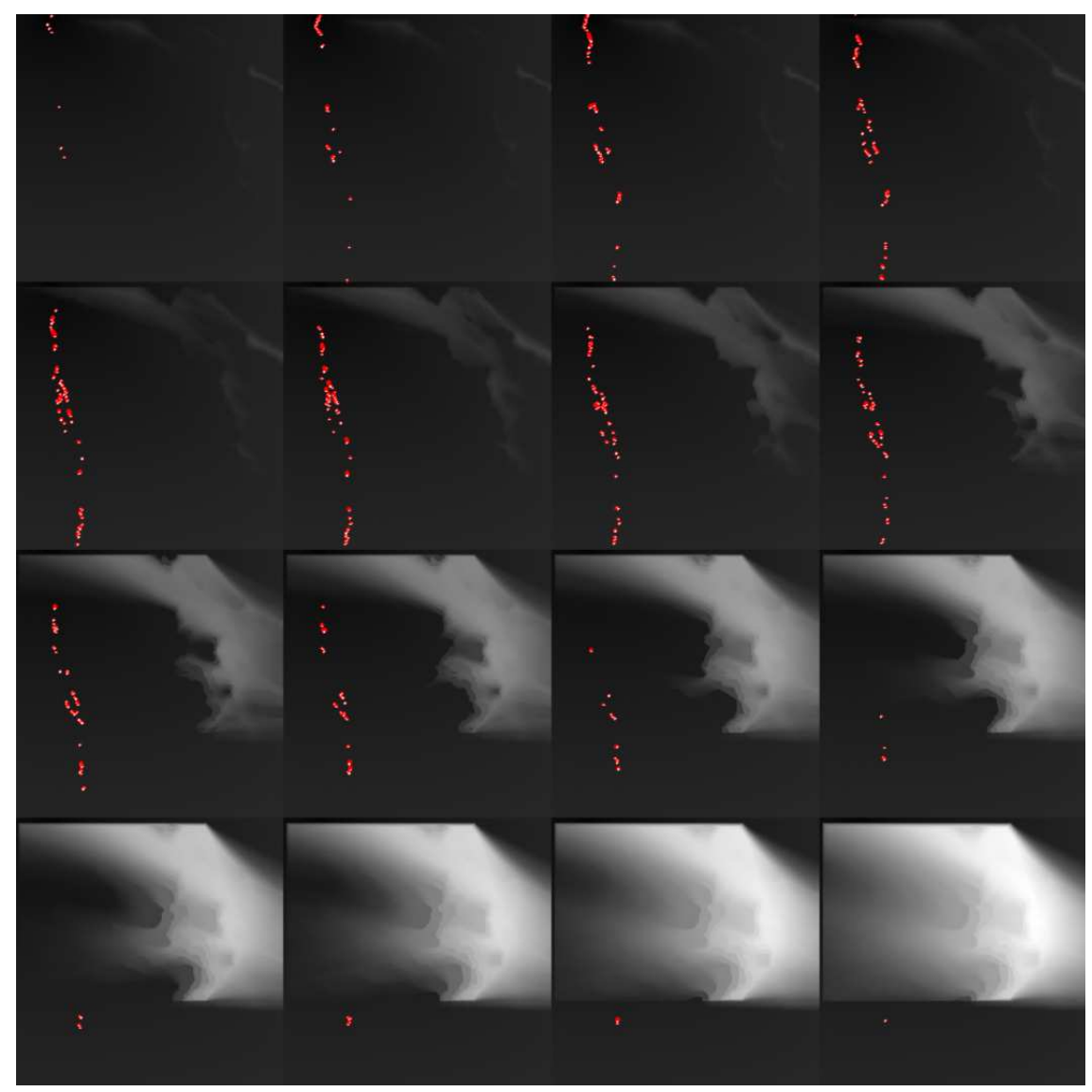

Fig. 6.: 16 cuts of the 3D path map, with the best Air path indicated in each layer (red dots), integration of all points, creates a continuous path, it is demonstrated on the next figure 6. (red path), individual cuts represent the minimal sum of the safety coefficients to each point of the area in each altitude layer, taken from the application developed by the authors.

Based on the selected sampling of input (entry) point in the AOA, there were calculated 105 optimal paths. All these paths are visualised in random colour on the figure 7, including its altitude profile and overlay with the map of AOA. It is apparent at the first look, that majority of the paths converge to the three air corridors indicating the alternative and the most safety areas. If we are searching for the best path and we are flexible in the entry and exit point selection, the bold red path was calculated as absolutely best option from the all possible candidates. This path includes also two alternative paths approximately in the middle third, which possess the same safety ratio. 


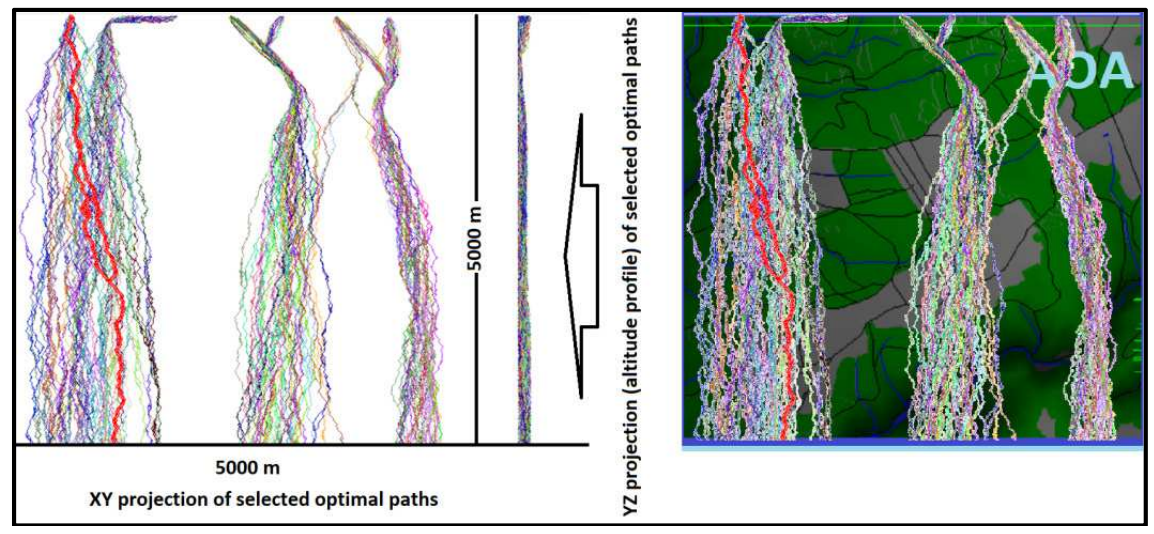

Fig. 7.: Illustration of 105 sub optimal Air paths, based on the entry of the "north" pane, the best path with the lowest sum of safety coefficients is highlighted by thick red dots, correspondence with $A O A$ is illustrated on the right.

More detailed altitude profile of the Air optimal path is presented on the figure 8. Looking at the altitude profile of all calculated paths, the altitude also indicates slight shape or limitation within its scope (close to the "north" plane, higher altitude is preferred), see figure 7 , in the middle.

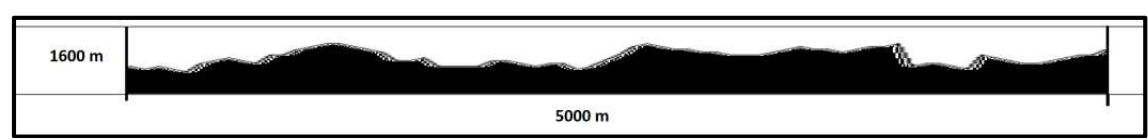

Fig. 8. Altitude profile of the final Air optimal path.

Explained approach was chosen to demonstrate a one of the possible way to the operational problem solution. It also shows the opportunity to operational task automation and its close relation with real time operational decision support in context of C4ISTAR systems or potentially UAV's operational autonomous/adaptive path planning.

The computer application, demonstrating the possible approach to the solution was executed on PC with INTEL Core-5 $(1,8 \mathrm{GHz})$ processor and the solution was found approximately within a 30 minutes, contemporary application also offers a large areas for optimization and highly parallel processing architecture implementation (GPU, CUDA and so.). 


\section{Conclusion}

As it was mentioned, the importance of effective automation of operational planning aspects in various areas (as a decision support component) is constantly on increase. It is necessary to say, that there appear a great potential in automation and optimization of operational tasks, which are closer to the human high-level reasoning instead of low-level engineering problems and Modelling and Simulation methods could be successfully applied. From this point of view a crucial aspect to evaluate an operational planning dealing with OPFOR and other players (e.g. civilians, neutral units, suspect ones) is strongly related to the ability to evaluate their behaviors; it is fundamental to create some effective models and behaviour that reproduce the actions/reactions based on the different boundary conditions. It is evident that use of Intelligent Agents driving objects during simulation enhance largely the effectiveness of simulation approach in this context as well as in other joint scenarios [15,16]. Also we have to understand, that almost any operational problem follows a pragmatic concept, what means the rationality in the relation to the human or certain side and the final achievement. Mainly it fulfils a fundamental criteria's of an optimization problem like maximization of profit or achievement under the condition of limited resources spending, like minimization of the task cost, time for execution, effort, danger areas explosion and so.

Presented solution shows the possible approach in operational problem solution dedicated to the air manoeuvre optimization in operational conditions with undefined starting and destination point, what means new dimension of options and calculations leading to a higher decision area then problems with selected constraints and known initial inputs.

\section{References}

1. Brian Geiger, UNMANNED AERIAL VEHICLE TRAJECTORY PLANNING WITH DIRECT METHODS, A Dissertation in Aerospace Engineering, The Pennsylvania State University , Pensylvania, USA 2009.

2. Waseem Ahmed Kamal, SAFE TRAJECTORY PLANNING TECHNIQUES FOR AUTONOMOUS AIR VEHICLES, A Dissertation work, University of Leicester, United Kingdom, 2005

3. Antonios Tsourdos, Brian White, Madhavan Shanmugavel, Cooperative Path Planning of Unmanned Aerial Vehicles, ISBN: 978-0-470-74129-0, 214 pages, WILEY, November 2010.

4. Duan, H. B., Ma, G. J., Wang, D. B., Yu, X. F., An improved ant colony algorithm for solving continuous space optimization problems. Journal of System Simulation, 19(5): 974-977, 2007.

5. Yao, H.Q., Quan P., Jian, G.Y., Flight path planning of UAV based on heuristically search and genetic algorithms, Proceedings of the IEEE 32nd Annual Conference,4550,2005 .

6. Liu, C.A., Li, W.J, Wang, H.P., Path planning for UAVs based on ant colony, Journal of the Air Force Engineering University, 2(5):9-12, 2004. 
7. M. Kress. Operational Logistics: The Art and Science of Sustaining Military Operations. Springer, 2002.

8. Mikulas Rybar. Modelovanie a simulacia vo vojenstve. Ministerstvo obrany Slovenskej republiky, Bratislava, 2000.

9. A. Washburn and M. Kress. Combat Modeling. International Series in Operations Research \& Management Science. Springer, 2009.

10. I. Mokrá. Modelový př́stup k rozhodovacím aktivitám velitelů jednotek v bojvých operacích. Disertační práce. Brno: Univerzita obrany v Brně, Fakulta ekonomiky a managementu, 2012. $120 \mathrm{~s}$.

11. MAZAL, Jan; STODOLA, Petr; PROCHÁZKA, Dalibor; KUTĚJ, Libor; ŠČUREK, Radomír; PROCHÁZKA, Josef. Modelling of the UAV safety manoeuvre for the air insertion operations. In: Modelling and Simulation for Autonomous Systems, MESAS 2016. Rome: Springer International Publishing, 2016, p. 337-346. ISSN 0302-9743. ISBN 978-3-319-47604-9.

12. M Rybansky: Modelling of the optimal vehicle route in terrain in emergency situations using GIS data. In: 8th International Symposium of the Digital Earth (ISDE8) 2013, Kuching, Sarawak, Malaysia 2014 IOP Conf. Series.: Earth Environmental Science 18 012071, doi:10.1088/1755-1315/18/1/012131, http://dx.doi:10.1088/17551315/18/1/012131. ISSN 1755-1307.

13. Rybanský, M. - Vala, M.: Relief Impact on Transport. In.: ICMT'09 - International conference on military technologies 2009, Brno (Czech Republic), 2009, 9 pp , ISBN 978-80-7231-649-6 (978-80-7231-648-9 CD).

14. DROZD, Jan; STODOLA, Petr; KŘIŠŤÁLOVÁ, Dana; KOZŮBEK, Jaroslav. Experiments with the UAS Reconnaissance Model in the Real Environment. In: Modelling and Simulation for Autonomous Systems. Cham: Springer International Publishing, 2018, p. 340-349. ISBN 978-3-319-76071-1.

15. BRUZZONE, Agostino. (2018) "MS2G as Pillar for Developing Strategic Engineering as a New Discipline for Complex Problem Solving", Keynote Speech at I3M, Budapest, September

16. BRUZZONE, Agostino, MASSEI, Marina (2017) "Simulation-Based Military Training", in Guide to Simulation-Based Disciplines, Springer, pp. 315-361 